FACULDADE DE CIÊNCIAS ECONÔMICAS dA UFRGS

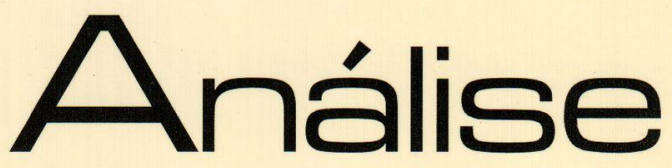

CRISES CAMBIAIS DOS ANOS 1990: UMA ANÁLISE SOB O ENFOQUE CUSTO BENEFICIO Ȧ BARRO-CORDON

TITO BELCHIOR S. MOREIRA, MAURÍCIO BARATA DE P. PINTO, GERALDO DA SILVA E SOUZA

LEI FUNDAMENTAL DA CONCORRÉNCIA CAPITALISTA E CRITÉRIO DE ADOCAO DE NOVAS TÉCNICAS

FRANCISCO PAULO CIPOLLA

CONCORRENCIA COMPORTAMENTO ESTRATÉGICO E. DESEMPENHO COMPETITIVO

ACHYLES BARCELOS DA COSTA

INCENTIVOS FISCAIS ISUDAM E SUFRAMA) E A DINÁMICA INDUSTRIAL E AGROPECUÁRIA NA REGIĀOO NORTE

LUIZ ROBERTO C. NASCIMENTO, IOÁO POLICARPO R. LIMA

VANTAGENS COMPARATIVAS MUNICIPAIS: INDICADORES E DETERMINANTES

MARCOS COSTA HOLANDA, FRANCIS CARIO PETTERINI

A CONTRIBUIÇÃO DO EMPRECO PÚBUICO NA GERAÇÃO DE POSTOS DE TRABALHO NOS PAISES DESENVOLVIDOS DESDE O POS CUERRA

FERNANDO AUCUSTO M. DE MATIOS

THE UIP HYPOTHESIS FOR ARCENTINA, BRAZIL, CHILE AND MEXICO WITH THE USE OF THE RATIONAI EXPECTAIION HYPOTHESIS. NEW EMPIRICAL EVIDENCE

JAIMILTON V CARVALHO, ADOLFO SACHSIDA, PAULO R. A. LOUREIRO, TIO BELCHIOR S. MOREIRA

A REUUGÁG UA JURNALA DE IRABAL HO EM MARX: POR QUE FALHAM AS PREVISÓES NOVO-KEYNESIANAS SOBRE OS IMPACTOS DESSA MEDIDA?

PAULO SÉRGIO FRACALANZA

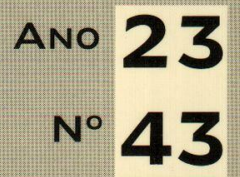

Março, 2005 
Universidade federal. do Rio Grande do Sul Reitor Prof. José Carlos Ferraz Hennemann

Faculdade de Ciências Econômicas

Diretor: Prof. Gentil Corazza

Centro de Estudos e Pesquisas Econômtcas

Diretor: Prof Lovois de Andrade Miguel

Departamento de Ciências Econômicas

Chefe: Prof. Ricardo Dathein

Departamento de Ciências Coniábeis e Atuariais

Chefe: Prof. Ceno Odilo Kops

Curso de Pós-Graduaçao em Economia

Coordenador: Prof. Femando Ferrari Filho

Curso de Pós-Graduação em Desenvolvimento

RuRAt.

Coordenador: Prof. Paulo Dabdab Waquil

Conseino Editorial: Carlos G A. Mielitz Netto (UFRGS), Eduardo A Maldonado Filho(UFRGS), Eduardo P. Ribeiro(UFRGS), Eleutério F. S. Prado (USP), Eugênio Lagemann (UFRGS), Fernando Cardim de Carvalho (UFRJ), Fernando Ferrari Filho (UFRGS), Fernando de Holanda Barbosa (FGV/RJ), Flávio Vasconcellos Comim (UFRGS), Gentil Corazza (UFRGS), Giácomo Balbinotto Netto (UFRGS), Gustavo Franco (PUC/RJ), Hélio Henkin (UFRGS), Jan A Kregel (UNCTAD), João Rogério Sanson(UFSC), Joaquim Pinto de Andrade (UnB), Jorge Paulo Araujo (UFRGS), Marcelo S. Portugal (UFRGS), Maria Alice Lahorgue (UFRGS), Paul Davidson (University of Tennessee), Paulo D. Waquil (UFRGS), Pedro C. D. Fonseca (UFRGS), Philip Arestis (University of Cambridge), Roberto C. Moraes (UFRGS), Ronald Otto Hillbrecht (UFRGS), Sérgio M. M. Monteiro (UFRGS), Sabino da Silva Porto Jr (UFRGS), Stefano Florissi (UFRGS) e Werner Baer (University of IHinois at Urbana - Champaign).

Comissão Enitorial: Eduardo Augusto Maldonado Filho, Fernando Ferrari Filho, Hélio Henkin, Marcelo Savino Portugal, Paulo Dabdab Waquil e Sérgio Marley Modesto Monteiro.
Eøiror: Sérgio Marley Modesto Monteiro

Eorror Adjunto: Hélio Henkin

Secretário: Emerson Douglas Neves

Revisĩo DE TEXros: Vanete Ricacheski.

Editoração: Núcleo de Editoração e Criaçâo da Gráfica da UFRGS - Janaína Horn e Junia Saedt

Fundador: Prof. Antônio Carlos Santos Rosa

Os materiais publicados na revista Análise Econômica são da exclusiva responsabilidade dos autores. É. permitida a reprodução total ou parcial dos trabalhos, desde que seja citada a fonte. Aceita-se permuta com revistas congêneres Aceitam-se, também, livros para divulgação, elaboração de resenhas e recensões. Toda correspondencia, material para publicação (vide normas na terceira capa), assinaturas e permutas devem ser dirigidos ao seguinte destinatário:

Prof. Sérgio Marley Modesto Monteiro Revista Analuse Económica - Av. João Pessoa, 52 CEP 90040-000 PORTO ALEGRE - RS, BRASIL. Telefones: (051) $33163513 / 33164164$ Fax: (051) 33163990 - E-mail: rae@vortex ufrgs.br

A Revista Análise Econômica agradece a colaboração dos pareceristas do número 43 , abaixo relacionados:

Adelar Fochezatto

Carlos Henrique Horn

Carlos Guilherme A. Mielitz Netto

Fabiana Fontes Rocha

Márcio Gomes Pinto Garcia

Maria de Lourdes Rollemberg Mollo

Maria Luiza Falcão Silva

Orlando Martinelli $\mathbf{J} \mathbf{r}$

Ricardo Dathein

Sabino da Silva Porto Jr

Samuel de Abreu Pessoa

Sérgio Marley Modesto Monteiro

\section{Análise Econômica}

Ano 23, n 43, março, 2005 - Porto Alegre

Faculdade de Ciências Econômicas, UJRGS, 2000

Periodicidade semestral, março e setembro.

1. Teoria Econômica - Desenvolvimento Regional -

Economia Agrícola - Pesquisa Teórica e Aplicada -

Periódicos. I. Brasil.

Faculdade de Ciências Econômicas,

Universidade Federal do Rio Grande do Sul. 


\title{
Crises cambiais dos anos 1990: uma análise sob o enfoque custo-benefício à Barro-Gordon'
}

\author{
Tito Belchior Silva Moreira . \\ Maurício Barata de P. Pinto " \\ Geraldo da Silva e Souza *"
}

Resumo: Este artigo tem por objetivo verificar se os países envolvidos nas principais crises cambiais dos anos 1990 seriam anunciados como vulneráveis às respectivas crises, com base em previsões levadas a cabo com uso de um escore de avaliação de crise definido pela função perda de BarroGordon (1983). Este escore de crise depende da inflação e do crescimento real do produto. É um construto definido com a utilização de métodos estatísticos de análise multivariada. Neste contexto os países da amostra são avaliados. Identificam-se os mais vulneráveis às crises cambiais por meio da análise de conglomerados. A classificação obtida é validada com o uso de análise discriminante. Os resultados são consistentes com os observados na literatura.

Palavras-chave: Modelo Barro-Gordon, crises cambiais, função perda, análise discriminante, análise de agrupamento.

\begin{abstract}
This article aims to verify if the countries involved in the main currency crises of the 90's would be announced as vulnerables to the respective crises, basing the predictions on a score of crisis evaluation defined by the loss function of Barro-Gordon (1983). This crisis score depends on inflation and on the GDP growth. It is a construct defined with the use of multivariate statistical methods. In this context the countries in the sample are evaluated. Cluster analysis is employed to identify the more vulnerable to currency crises. This classification is validated via discriminant analysis. The results are consistent with the literature.
\end{abstract}

Keywords: Barro-Gordon Model, currency crises, loss function, discriminant analysis, cluster analysis.

JEL Classification: F30, F41

* Universidade Católica de Brasilia: tito@pos.ucb.br

** Universidade de Brasília: mauriciopinto@brturbo.com e geraldosouza@unb.br

' Os autores agradecem à colaboração de José R. Novaes, Maria L. Falcão, Geraldo Sant'ana de C Barros e dos anônimos pareceristas pelos pertinentes comentários. Erros, ora remanescentes, sâo de inteira responsabilidade dos autores. 


\section{Introdução}

Nos anos 1990, as mutações na economia mundial propiciaram o desenvolvimento de novas teorias explicativas de ataques especulativos e das crises deles advindas. Uma das teorias apresentadas na literatura é que uma crise pode surgir mesmo que a economia apresente bons fundamentos macroeconômicos, assumindo características de crises auto-realizáveis. Está implícita nesse argumento a pressuposição de que a política econômica não é predeterminada, mas responde às mudanças da economia, isto é, a política econômica é um jogo interativo entre os agentes e os formuladores de política.

Nesses modelos de crises auto-realizáveis - também conhecidos como modelos de segunda geração - as expectativas e ações dos agentes econômicos podem afetar algumas variáveis, e, como em um jogo seqüencial, os formuladores de políticas econômicas respondem a posteriori. Isso cria a possibilidade de equilíbrios múltiplos, de modo que a economia possa se mover sem a necessidade de mudanças nos seus principais fundamentos.

Crises cambiais podem ocorrer devido à antecipação de uma mudança no regime de taxa đe câmbio pelos agentes econômicos. Mudanças nas expectativas podem levar a um comportamento que force o colapso do regime cambial, validando as próprias expectativas previamente criadas pelos agentes. Isso justifica por que esses modelos de crises são auto-realizáveis.

O modelo de Barro e Gordon (1983) - precursor dos modelos de segunda geração - enfoca a relação custo e benefício para analisar se as políticas econômicas são críveis. Os autores revelam a existência de tensão entre as autoridades monetárias e os agentes econômicos, como observado em muitos países. Os agentes, provavelmente, concordam com a meta da autoridade de obter maior taxa de emprego combinada com menor taxa de inflação. Mas, certamente, eles desejam evitar serem surpreendidos com uma taxa de inflação acima das suas expectativas, de forma a reduzir a sua renda real. $\mathrm{O}$ aspecto principal desse modelo é a permuta de desemprego por inflação.

Os modelos de crises cambiais de segunda geração são uma mistura do modelo de crise nos fundamentos de Krugman (1979) e Flood e Garber (1984) com o enfoque de custo e benefício de Barro e Gordon (1983). O principal aspecto desses modelos é a permuta de inflação por desemprego ou a permuta de inflação por déficit público (ANDRADE e FALCÃO, 1999). 
Nesses modelos, a autoridade monetária procura minimizar uma função de perda que se constitui, por exemplo, da soma do quadrado do desvio entre a inflação corrente e a meta inflacionária com o quadrado do desvio entre a taxa de desemprego corrente e a taxa de desemprego natural. Num regime de taxas de câmbio fixas, pode ocorrer uma situação de pequeno desvio da taxa de desemprego em relação à taxa natural, mas às custas de elevadas taxas de inflação. Esse processo pode resultar na inviabilização da manutenção do regime de câmbio fixo. Elevadas taxas de inflação significam problemas nos fundamentos.

Pode ocorrer uma situação inversa àquela anteriormente descrita. A economia pode apresentar bons fundamentos com baixa taxa de inflação mas às custas de elevadas taxas de desemprego. Nesse caso, os agentes econômicos também podem avaliar que a política econômica não é crível, o que gera expectativa de que o governo irá abandonar a taxa de câmbio fixa. Nesse contexto, políticas não críveis reduzem a credibilidade das autoridades monetárias de forma que, se vários investidores acreditarem que o sistema cambial vai entrar em colapso, a crise irá se materializar.

Nos dois exemplos supracitados, haverá o abandono do regime de câmbio fixo. A diferença é que, quando a autoridade monetária prioriza baixos níveis de desemprego, às custas de elevados índices inflacionários, o regime cambial entra em colapso em função de problemas nos fundamentos macroeconômicos. Esse caso assemelha-se aos modelos de primeira geração. Inversamente, mesmo quando os fundamentos macroeconômicos (baixos níveis inflacionários) apresentam-se em conformidade com um regime de câmbio fixo, mas às custas de elevadas taxas de desemprego, mesmo assim o regime cambial poderá entrar em colapso. Esse caso não é explicado pelos modelos de primeira geração. Se os agentes econômicos avaliarem que o custo para manutenção do câmbio fixo (recessão e desemprego) é supérior ao benefício gerado por ela (estabilidade dos preços), então tais agentes gerarāo expectativas de que o governo irá abandonar a taxa de câmbio fixa, de forma que estas expectativas poderão se tornar realidade. Esse segundo caso é explicado pelos modelos de segunda geração.

Assim, contrariamente aos modelos de primeira geração, em que os ataques especulativos são resultados de desequilíbrios nos fundamentos, Obstfeld e Rogoff (1997) e Velasco (1996), entre outros que contribuíram para a formalização dos modelos de segunda geração, defendem a possibilidade de uma crise cambial começar como resulta- 
do de expectativas auto-realizáveis, mesmo quando as economias apresentam bons fundamentos (baixas taxas de inflação, mas às custas de elevadas taxas de desemprego). Trata-se do caso das crises dos países do Sistema Monetário Europeu - SME - em 1992 e 1993.

Quando houve a unificação da Alemanha Ocidental com a Oriental em 1988, o custo do processo de unificação gerou forte pressão sobre as contas do governo, obrigando-o a financiar o déficit fiscal via emissão de moeda. O banco central alemão implementou uma política monetária restritiva para evitar inflação. Em conseqüência, a taxa de juros alemã elevou-se acima das demais taxas dos países pertencentes ao SME. Esses países alinharam suas taxas de juros à taxa alemã, de forma que resultou em elevadas taxas de desemprego. Embora tais países possuíssem bons fundamentos, com baixas taxas de inflação em acordo com regimes de câmbio fixo (administrado), os agentes econômicos perceberam que tal política não se manteria por muito tempo, pois, mais cedo ou mais tarde, um daqueles países abandonaria o câmbio fixo em decorrência dos custos gerados por tal política ser maior do que seus benefícios.

Os países pertencentes ao SME que abandonassem o câmbio fixo mais tardiamente incorreriam em maiores perdas, seja porque teriam maiores perdas de reservas para defender o câmbio fixo, ou porque incorreriam em maiores perdas caso elevassem ainda mais as taxas de juros para defender o regime cambial. Taxas de juros mais elevadas gerariam mais recessão e mais desemprego. Como em um jogo interativo, os agentes econômicos (especuladores, formuladores de políticas econômicas etc) avaliaram a situação como insustentável, de forma que a expectativa do abandono do regime de câmbio fixo tornou-se realidade.

A idéia dos modelos de profecias auto-realizáveis está relacionada com a credibilidade das políticas implementadas e administradas pela autoridade monetária. A manutenção de suas políticas, num regime de taxa de câmbio fixa, é crível enquanto os benefícios gerados por elas forem maiores que os custos. Essa relação entre custos e benefícios é representada por uma função de perda. A exemplo do modelo de Barro e Gordon (1983), que apresenta na sua função de perda a permuta de inflação por desemprego, menores taxas de inflação e menores taxas de desemprego (maiores taxas de crescimento do produto) minimizam 
as perdas para a sociedade. Menores perdas implicam maior credibilidade às políticas engendradas pelos formuladores de políticas econômicas. ${ }^{2}$

Destaque-se que uma perda de controle da inflação - problemas nos fundamentos - poderia também gerar falta de credibilidade das autoridades monetárias, que, por sua vez, poderia alimentar as expectativas de que o sistema cambial vai entrar em colapso. Isto caracteriza uma economia susceptível a crises de fundamentos e auto-realizável. Neste contexto, pode-se considerar que a origem da crise está nos fundamentos. Ao longo do artigo vamos nos referir a crises cujas origens estão nos fundamentos $\mathrm{e}$ crises cujas origens estão em políticas econômicas não críveis, mesmo com bons fundamentos. Ambas podem gerar crises autorealizáveis.

Neste artigo, objetiva-se estimar a função de perda nos moldes do modelo de Barro e Gordon (1983), de forma que, com base no valor das perdas de cada um dos 28 países da amostra, se obtenha a classificação dos países associada ao resultado das perdas. Quanto maior a perda para um determinado país, maior a possibilidade de ocorrência de crise cambial. Se as perdas forem originadas por elevadas taxas de inflação, então se atribui a provável crise a problemas nos fundamentos macroeconômicos. $\mathrm{Se}$ as perdas forem originadas de elevadas taxas de desemprego, associadas a baixas taxas de inflação, então se atribui a provável crise a falta de credibilidade para a manutenção da política de câmbio fixo ou administrado. Por outro lado, os países que apresentarem menores perdas serão considerados os menos susceptíveis às crises cambiais.

\section{Metodologia}

Essencialmente a abordagem para a avaliação de crise cambial envolve a caracterização de um índice de crise unidimensional. Define-se como indicador de crise cambial agregada a quantidade

$$
I=\sum_{i=1}^{n} \psi_{i} \gamma_{i} X_{i}
$$

\footnotetext{
${ }^{2}$ Uma resenha sobre crises cambiais e financeiras pode ser vista em Moreira (2002)
} 
onde $\mathrm{n}=4, \gamma_{\mathrm{i}}$ é direção (sinal) estabelecida a priori para $\mathrm{X}_{\mathrm{i}} \mathrm{e}$

$$
\Psi_{i}^{\prime}=\frac{R_{i}^{2}}{\sum_{j=1}^{n} R_{\mathrm{j}}^{2}}
$$

onde $R_{1}^{2}$ representa o coeficiente de determinação da regressão de $\mathrm{X}_{\mathrm{i}}$ nas demais variáveis.

O indicador $I$ é semelhante a um fator geral num modelo de análise fatorial, onde $\psi_{i}$ é, aproximadamente, a comunalidade relativa da variável $\mathrm{X}_{\mathrm{i}}$, (WICHERN e JOHNSON, 1998) e (HARMAN, 1976). Outra analogia seria definida pelo escore do primeiro componente na análise de componentes principais (MANLY, 1994). Os valores de I permitem ordenar os elementos da amostra, países da amostra, segundo a intensidade com que respondem a esta medida agregada de crise.

A disponibilidade da medida de crise agregada I leva naturalmente à investigação sobre a existência de grupos homogêneos, i.e., de conglomerados de países com valores similares ao escore. A abordagem neste aspecto utiliza o método de classificação de Ward (EVERITT e DUNN, 2001) e a distância euclidiana como medida de proximidade entre grupos. A técnica de Ward é um método de classificação hierárquico que procura formar agrupamentos com a menor variabilidade possivel dentro dos grupos. O critério tem um princípio similar ao da análise de variância multivariada. Conclui-se pela existência de 2 grupos homogêneos, conforme seção 5.1. A escolha formal do número de estratos de crise (2) baseou-se nas estatísticas comumente utilizadas na análise de agrupamentos (CCC e R2), conforme Everitt e Derr (1996). Esta classificação dicotômica, sugerida pelo processo de classificação, foi validada com o uso de análise discriminante (TABACHNICK e FIDELL, 2001). Esta mesma metodologia empregada por Moreira (2003) e Moreira (forthcoming).

\section{Função de perda de Barro-Gordon (1983)}

O objetivo do formulador de políticas e da sociedade para cada período é sintetizado por uma função perda $Z_{t}$, a qual aumenta em função de qualquer desvio da taxa de desemprego em relação à taxa natural e também de qualquer desvio da inflação em relação à meta inflacionária, que é assumida como nula (BARRO-GORDON, 1983). A equação (3.1) reflete o comportamento minimizador da autoridade monetária. Admite-se uma 
simples função quadrática na seguinte forma:

$\mathrm{Z}_{\mathrm{t}}=\mathrm{a}\left(\mathrm{U}_{\mathrm{t}}-\mathrm{kU_{ \textrm {t } }}\right)^{2}+\mathrm{b}\left(\Pi_{\mathrm{t}}\right)^{2}$

onde: $\mathrm{a}, \mathrm{b}>0, \quad 0 \leq \mathrm{k} \leq 1$.

Para efeito de simplificação, assume-se que a taxa de desemprego natural é nula, de forma que

$Z_{t}=a\left(U_{t}\right)^{2}+b\left(\Pi_{t}\right)^{2} ; \quad a>0, b>0$

Ao trabalhar com uma amostra de 28 países, surge um problema operacional. Geralmente, os países possuem metodologia própria para apuração da taxa de desemprego, o que enviesa a comparação das taxas entre eles. Assim, sabendo que a taxa de desemprego tem uma relação inversa com a taxa de crescimento do produto real, uma aproximação da lei de Okun, resolve-se o problema tal que:

$\mathrm{U}_{\mathrm{t}}=-\mathrm{d}\left[\mathrm{y}_{\mathrm{t}}\right] ; \quad \mathrm{d}>0$

indicando que um dado incremento da taxa de crescimento do produto real $\left(\mathrm{y}_{\mathrm{t}}\right)$ leva a uma redução da taxa de desemprego. Substituindo (3.3) em (3.2), tem-se que:

$\mathrm{Z}_{\mathrm{t}}=\mathrm{a}\left[-\mathrm{d}\left(\mathrm{y}_{\mathrm{t}}\right)\right]^{2}+\mathrm{b}\left[\Pi_{\mathrm{t}}\right]^{2}$

Sem prejuízo ao resultado, pode-se representar a equação acima como:

$\mathrm{Z}_{\mathrm{t}}=\mathrm{g}(\mathrm{y})^{2}+\mathrm{b}\left(\Pi_{\mathrm{t}}\right)^{2}$

onde: $a(-d)^{2}=g>0$.

Analogamente temos que:

$\mathrm{Z}_{\mathrm{t}-1}=\mathrm{h}\left(\mathrm{y}_{\mathrm{t}-1}\right)^{2}+\mathrm{c}\left(\Pi_{\mathrm{t}-1}\right)^{2}$, onde $\mathrm{h}, \mathrm{c}>0$

Assim, somando (3.5) e (3.6), temos:

$\mathrm{V}=\mathrm{g}\left(\mathrm{y}_{\mathrm{l}}\right)^{2}+\mathrm{h}\left(\mathrm{y}_{\mathrm{t}-1}\right)^{2}+\mathrm{b}\left(\Pi_{\mathrm{t}}\right)^{2}+\mathrm{c}\left(\Pi_{\mathrm{t}-1}\right)^{2}$

onde $Z_{\mathrm{t}}+Z_{\mathrm{t}-1}=\mathrm{V}$ é a função de perda que será estimada.

\section{Base de dados e critério de seleção de países}

Trabalha-se com uma amostra de 28 países, cujo critério de escolha envolve dados de países nos dois anos anteriores às principais crises cambiais dos anos 1990. Pretende-se verificar se os países 
selecionados serão anunciados como vulneráveis às respectivas crises, com base na estimativa da função de perda à BarroGordon (1983).

A seguir, relacionam-se os países associados às respectivas crises cambiais dos anos 1990 e o biênio relativo aos dados da taxa de crescimento do produto real e da taxa de inflação de cada país.

I) Crise do Sistema Monetário Europeu (SME) deflagrada em agosto de 1992: Bélgica (91/92), Dinamarca (91/92), Espanha (91/92), França (91/92), Itália (91/92), Reino Unido(91/92) e Suécia (91/92);

II) Crise do leste asiático deflagrada em julho de 1997: Coréia (95/96), Filipinas (95/96), Indonésia (95/96), Malásia (95/96), Tailândia (95/96), Argentina (95/96), Brasil (95/96), Chile (95/96), China (95/96), Cingapura (95/96), Colômbia (95/96), Hong-Kong (95/ 96), Jordânia (95/96), México (95/96), Peru (95/96), República Tcheca (95/96), Sri Lanka (95/96), Turquia (95/96) e Venezuela (95/96);

III) Crise do México deflagrada em dezembro de 1994: México (1993/94);

IV) Crise do Brasil deflagrada em janeiro de 1999: Brasil (97/98).

Pode-se verificar que há uma quantidade maior de países no grupo relacionado à crise do leste asiático, justificado pelo fato de ela ter tido um maior impacto e difusão entre os países emergentes.

A fonte de dados baseia-se nas Revistas do Fundo Monetário Internacional, International Financial Statistics, (IFS, 1999). A inflação é calculada com base no Índice de Preço ao Consumidor (linha 64) e a taxa de crescimento do produto real é calculada com base no PNB (linha 99bvp).

\section{Resultados e análises}

A Tabela 1 apresenta as comunalidades relativas de cada variável, conforme segue.

Tabela 1: Comunalidades relativas da função perda de Barro-Gordon

\begin{tabular}{clc}
\hline Variáveis & $\mathbf{R}_{1}{ }^{2}(\%)$ & Comunalidade relativa $\psi_{i}(\%)$ \\
\hline$\left(\Pi_{t-1}\right)^{2}$ & 23,7684 & 18,41840 \\
$\left(\Pi_{t}\right)^{2}$ & 27,5453 & 21,34516 \\
$\left(\mathrm{y}_{t-1}\right)^{2}$ & 37,3487 & 28,94193 \\
$\left(\mathrm{y}_{\mathrm{t}}\right)^{2}$ & 40,3846 & 31,29448 \\
\hline Total & 129,0470 & $\mathbf{1 0 0 , 0 0 0 0 0}$ \\
\hline
\end{tabular}


Como já foi determinado o peso (comunalidade relativa) de cada variável na Tabela 1 , criar-se-á um escore que medirá a função perda de Barro-Gordon (1983) para um conjunto de 28 países. Dessa forma, define-se o escore da função perda como:

\section{Escore}

$$
\text { (I) }=\psi_{1}^{*}\left(\Pi_{\mathrm{t}}\right)^{2}+\psi_{2}^{*}\left(\Pi_{\mathrm{t}-1}\right)^{2}-\psi_{3}^{*}\left(\mathrm{y}_{\mathrm{t}}\right)^{2}-\psi_{4} *\left(\mathrm{y}_{\mathrm{t}-1}\right)^{2}
$$

onde $\psi_{i}(i=1,2,3,4)$ são os pesos das variáveis apresentadas na Tabela 1 e os valores das variáveis padronizadas são apresentados na Tabela 2. Assim, o escore de cada país é determinado por uma média das variáveis padronizadas ponderadas pelas suas respectivas comunalidades relativas (pesos).

Percebe-se que os pesos do desvio da inflação e do produto são iguais para todos os países. Em geral as economias que não cuidam dos fundamentos têm um peso menor para os desvios da inflação e vice-versa. Nesse contexto as comunalidades relativas estariam superestimando ou subestimando os pesos de cada economia, respectivamente, o que geraria vieses nos valores dos escores. A despeito desta restrição metodológica, faz-se mister ressaltar, encontramos resultados consistentes com a literatura. Esta constatação pode ser feita porque estamos avaliando as crises ex-post e, deste modo, pode-se comparar os resultados obtidos pela metodologia aqui proposta com os resultados de outros estudos empíricos.

As perdas serão minimizadas com menores taxas de inflação e menores taxas de desemprego (maiores taxas de crescimento real do produto). Dessa forma, admite-se que menores escores significam menores perdas e, inversamente, maiores escores significam maiores perdas. Com o sinal do coeficiente do crescimento real do produto negativo, quanto maior o crescimento do produto, isto é, quanto menor a taxa de desemprego, menor será o escore; e com o sinal do coeficiente da inflação positivo, quanto menor a inflação menor o escore. Portanto, menores escores indicam minimização da função de perda.

Assim, menor perda na função da Autoridade Monetária sinaliza uma política econômica crível, melhorando os atributos credibilidade e reputação. Portanto, a credibilidade das políticas econômica será inversamente proporcional aos escores. Quanto maior o valor do escore, menor a credibilidade das políticas engendradas pelos seus formuladores, em função de elevadas 
taxas de desemprego e/ou elevadas taxas de inflação. Os altos índices de inflação também sinalizam problemas nos fundamentos macro-econômicos do país.

A literatura avaliou que a crise do SME é um exemplo típico de crises auto-realizáveis, explicadas pelos modelos de segunda geração, conforme trabalhos de Knot, Sturm e Haan (1998), Rose e Svensson (1994), Obstfeld e Rogoff (1995) e Krugman (1996) e Eichengreen (2000). Assim sendo, ao estimar a função de perda de Barro e Gordon, pode-se atestar se realmente os países do SME serão classificados como vulneráveis às crises de profecias auto-realizáveis, e se os principais protagonistas da crise asiática (Coréia, Filipinas, Indonésia, Malásia e Tailândia) não serão classificados como suscetíveis a este tipo de crise. A crise do leste asiático é explicada por problemas no setor financeiro e no balanço de pagamentos, crises gêmeas, (KAMINSKY e REINHART, 1999).

A Tabela 2, apresentada a seguir, retrata os valores padronizados referentes às variáveis da função de perda de Barro-Gordon (1983) para 28 países.

Tabela 2: Valores padronizados das variáveis da função de perda de Barro-Gordon

\begin{tabular}{lcccc}
\hline $\begin{array}{c}\text { Países e biênio } \\
\text { pré-crise }\end{array}$ & $\left(\Pi_{t-1}\right)^{2}$ & $\left(\Pi_{t}\right)^{2}$ & $\left(y_{t-1}\right)^{2}$ & $\left(y_{t}\right)^{2}$ \\
\hline Argentina-95/96 & $-0,358552$ & $-0,476577$ & $-1,63056$ & 0,586735 \\
Bélgica-91/92 & $-0,352200$ & $-0,416876$ & $-0,510157$ & $-0,669155$ \\
Brasil-95/96 & 2,251110 & $-0,0575234$ & $-0,108572$ & $-0,223765$ \\
Brasil-97/98 & $-0,235760$ & $-0,399197$ & $-0,156162$ & $-1,077270$ \\
Chile-95/96 & $-0,176044$ & $-0,2984910$ & 1,564080 & 1,215710 \\
China-95/96 & $-1,244500$ & $-1,4093100$ & 1,538710 & 1,923960 \\
Cingapura-95/96 & $-0,402671$ & $-0,441924$ & 1,086040 & 1,349560 \\
Colômbia-95/96 & 0,254979 & 0,0700988 & 0,372370 & $-0,510786$ \\
Coréia-95/96 & $-0,313830$ & $-0,353182$ & 1,135970 & 1,015880 \\
Dinamarca-91/92 & $-0,377534$ & $-0,424416$ & $-0,650309$ & $-0,795289$ \\
Espanha-91/92 & $-0,265244$ & $-0,329876$ & $-0,486718$ & $-0,983558$ \\
Filipinas-95/96 & $-0,199385$ & $-0,245397$ & 0,106716 & 0,685301 \\
França-91/92 & $-0,355378$ & $-0,416876$ & $-0,835894$ & $-0,795289$ \\
Hong Kong - 95/96 & $-0,165994$ & $-0,316842$ & $-0,108572$ & 0,260203 \\
Indonésia-95/96 & $-0,152552$ & $-0,272067$ & 0,961616 & 1,416670 \\
Itália-91/92 & $-0,255444$ & $-0,350602$ & $-0,720076$ & $-1,014830$ \\
Jordânia-95/96 & $-0,383837$ & $-0,311611$ & 0,396658 & $-0,920926$ \\
Malásia-95/96 & $-0,288004$ & $-0,389040$ & 1,261200 & 1,618750 \\
\hline & & & & \\
\hline
\end{tabular}


(Continuação...)

\begin{tabular}{lcccc}
\hline $\begin{array}{c}\text { Países e biênio } \\
\text { pré-crise }\end{array}$ & $\left(\Pi_{t-1}\right)^{2}$ & $\left(\Pi_{t}\right)^{2}$ & $\left(y_{t-1}\right)^{2}$ & $\left(y_{t}\right)^{2}$ \\
\hline México-93/94 & $-0,135679$ & $-0,30112$ & $-0,533573$ & 0,065776 \\
México-95/96 & 0,8060370 & 0,14431 & $-2,375610$ & 0,488449 \\
Peru-95/96 & $-0,0914511$ & $-0,177647$ & 0,739100 & $-0,383532$ \\
Reino Unido-91/92 & $-0,268504$ & $-0,383947$ & $-1,338680$ & $-1,139590$ \\
R.Tcheca-95/96 & $-0,165994$ & $-0,250751$ & 0,518443 & 0,065776 \\
Sri-Lanka-95/96 & $-0,212655$ & $-0,0546757$ & 0,299644 & 0,0334804 \\
Suécia-91/92 & $-0,179388$ & $-0,421905$ & $-1,361270$ & $-1,633680$ \\
Tailândia-95/96 & $-0,271762$ & $-0,329876$ & 1,110990 & 0,5867350 \\
Turquia-95/96 & 3,44438 & 2,28973 & 0,714491 & 1,082360 \\
Venezuela-95/96 & 1,94502 & 3,20559 & $-0,0847432$ & $-1,232840$ \\
\hline
\end{tabular}

A Tabela 3 apresenta os escores, de forma a indicar as economias mais susceptiveis às crises pelo enfoque custo-benefício à BarroGordon.

Tabela 3: Escores estimados: função perda de Barro-Gordon (28 países)

\begin{tabular}{cccc}
\hline China-95/96 & Filipinas-95/96 & Colômbia-95/96 & Itália-91/92 \\
-1,57746 & $-0,33445$ & 0,11400 & 0,40410 \\
Malásia-95/96 & R.Tcheca-95/96 & Argentina-95/96 & Brasil-95/96 \\
$-1,00768$ & $-0,25473$ & 0,12054 & 0,50379 \\
Chile-95/96 & Peru-95/96 & Bélgica-91/92 & Turquia-95/96 \\
$-0,92926$ & $-0,14865$ & 0,20321 & 0,57764 \\
Cingapura-95/96 & H. Kong-95/96 & Brasil-97/98 & R. Unido-91/92 \\
$-0,90515$ & $-0,14821$ & 0,25369 & 0,61266 \\
Indonésia-95/96 & Sri Lanka-95/96 & Dinarrarca-91/92 & Suécia-91/92 \\
$-0,80782$ & $-0,14804$ & 0,27697 & 0,78213 \\
Coréia-95/96 & Jordânia-95/96 & Espanha-91/92 & México-95/96 \\
$-0,77987$ & 0,03619 & 0,32940 & 0,79296 \\
Tailândia-95/96 & México-93/94 & França-91/92 & Venezuela-95/96 \\
-0,62563 & 0,04458 & 0,33637 & 1,45282 \\
\hline
\end{tabular}

Embora os países com escores negativos, a princípio possam caracterizar-se como aqueles menos susceptiveis às crises cambiais pelo enfoque de custo-benefício de Barro e Gordon (1983), é necessário utilizar um método estatístico para classificar as economias 
menos vulneráveis a esse tipo de crise. No tópico seguinte será aplicado o método de análise de agrupamento para este fim.

\subsection{Análise de agrupamento}

Os resultados demonstram, com base nas estatísticas necessárias para selecionar o número adequado de conglomerados, a existência de dois grupos.

Grupo 1 - Argentina-95/96, Bélgica-91/92, Brasil-95/96, Brasil-97/98, Colômbia-95/96, Dinamarca-91/92, Espanha-91/92, Filipinas-95/96, França-91/92, Hong Kong-95/96, Itália-91/92, Jordânia-95/96, México-93/94, México-95/96, Peru-95/96, Reino-Unido-91/92, República Tcheca-95/96, Sri Lanka-95/96, Suécia-91/92, Turquia-95/96 e Venezuela-95/96.

Grupo 2 - Chile-95/96, China-95/96, Cingapura-95/96, Coréia95/96, Indonésia-95/96, Malásia-95/96 e Tailândia-95/96.

Pode-se concluir que os países do $2^{\circ}$ grupo, os quais possuem os menores escores, são menos sujeitos às crises cambiais, seja devido a políticas macroeconômicas não críveis, seja devido a problemas nos fundamentos. Menores escores são resultantes de menor desvio da inflação (nesse caso as economias são menos susceptiveis a crises decorrente de problemas nos fundamentos) e maiores desvios do produto, que é uma proxy para maiores desvios do emprego ou menores desvios do desemprego, o que torna a política crível, conferindo maior credibilidade para as autoridades monetárias. Portanto, economias que apresentam menores escores são menos susceptíveis a crises auto-realizáveis.

Inversamente, o conjunto de países com escores mais elevados - pertencentes ao $1^{\circ}$ grupo - apresentam menor credibilidade e estão sujeitos às crises auto-realizáveis, seja devido a problemas nos fundamentos ou a políticas econômicas não críveis.

Para testar se realmente os dois grupos de países são distintos entre si, utilizar-se-á a análise de variância apresentada a seguir.

\subsection{Análise de variância}

O valor da estatística $F(1,27)=51$ é estatisticamente significante, rejeitando a hipótese nula que estabelece a não distinção entre os dois grupos ou conglomerados. Confirmada a distinção entre os conglomerados, aplicar-se-á o método de análise discriminante para confirmar se os países com os grupos previamente determinados pela 
análise de agrupamento foram corretamente alocados em seus respectivos conglomerados.

\subsection{Análise discriminante}

A adequada classificação dos países nos respectivos grupos, e as probabilidades de ocorrência dela, pode ser verificada na Tabela 4. Nessa Tabela observa-se na primeira coluna da esquerda a relação dos 28 países da amostra. Ao lado de cada país relacionado, indica-se o biênio anterior às respectivas crises em que é estimado o escore da função de perda de cada economia. Na segunda coluna observam-se os países classificados, preliminarmente, nos seus respectivos grupos, de acordo com o método de análise de agrupamento. A terceira coluna mostra para que grupo o método de análise discriminante alocou cada um dos países. Pode-se observar que apenas Filipinas95/96 foi realocada do grupo 1 para o grupo 2. Os demais países foram alocados em acordo com os resultados da análise de agrupamento. As duas últimas colunas apresentam as probabilidades de os países serem alocados nos respectivos grupos. A Argentina, por exemplo, possui $96,43 \%$ de chance de pertencer ao $1^{\circ}$ grupo.

Tabela 4: Classificação dos países - função discriminante linear

\begin{tabular}{lcccc}
\hline Países & Do grupo & $\begin{array}{c}\text { Para o } \\
\text { grupo }\end{array}$ & Probabilidade de Classificação \\
\hline Argentina-95/96 & 1 & & Grupo 1 & Grupo 2 \\
Bélgica-91/92 & 1 & 1 & 0,9643 & 0,0357 \\
Brasil-95/96 & 1 & 1 & 0,9801 & 0,0199 \\
Brasil-97/98 & 1 & 1 & 0,9979 & 0,0021 \\
Chile-95/96 & 2 & 1 & 0,9862 & 0,0138 \\
China-95/96 & 2 & 2 & 0,0112 & 0,9888 \\
Cingapura-95/96 & 2 & 2 & 0,0001 & 0,9999 \\
Colômbia -95/96 & 1 & 2 & 0,0133 & 0,9867 \\
Coréia-95/96 & 2 & 1 & 0,9626 & 0,0374 \\
Dinamarca-91/92 & 1 & 2 & 0,0331 & 0,9669 \\
Espanha-91/92 & 1 & 1 & 0,9883 & 0,0117 \\
Filipinas-95/96 & 1 & 1 & 0,9920 & 0,0080 \\
França-91/92 & 1 & $2 *$ & 0,4446 & 0,5554 \\
Hong Kong-95/96 & 1 & 1 & 0,9924 & 0,0076 \\
\hline
\end{tabular}


(Continuação...)

\begin{tabular}{lcccc}
\hline Países & Do grupo & $\begin{array}{c}\text { Para o } \\
\text { grupo }\end{array}$ & Probabilidade de Classificação \\
\hline Indontósia-95/96 & 2 & Grupo 1 & Grupo 2 \\
Indália-91/92 & 1 & 2 & 0,0270 & 0,9730 \\
Jordânia-95/96 & 1 & 1 & 0,9955 & 0,0045 \\
Malásia-95/96 & 2 & 1 & 0,9359 & 0,0641 \\
México-93/94 & 1 & 2 & 0,0063 & 0,9937 \\
México-95/96 & 1 & 1 & 0,9395 & 0,0605 \\
Peru-95/96 & 1 & 1 & 0,9998 & 0,0002 \\
R. Unido-91/92 & 1 & 1 & 0,7848 & 0,2152 \\
R.Tcheca-95/96 & 1 & 1 & 0,9991 & 0,0009 \\
Sri Lanka-95/96 & 1 & 1 & 0,6104 & 0,3896 \\
Suécia-91/92 & 1 & 1 & 0,7856 & 0,2144 \\
Tailândia-95/96 & 2 & 1 & 0,9998 & 0,0002 \\
Turquia-95/96 & 1 & 2 & 0,1009 & 0,8991 \\
Venezuela-95/96 & 1 & 1 & 0,9988 & 0,0012 \\
\hline
\end{tabular}

\subsection{Análise do Grupo 1}

Os países que pertencem ao Grupo 1 estão susceptíveis às crises cambiais com base na função de perda de Barro-Gordon, seja por problemas nos fundamentos macroeconômicos (elevadas taxas de inflação), seja pela adoção de políticas macroeconômicas não críveis (baixas taxas inflacionárias às custas de elevadas taxas de desemprego ou baixo crescimento real do produto) por parte dos formuladores de políticas. O problema agora é separar os países do grupo 1 em dois subgrupos: um subgrupo de economias mais susceptivel a problemas nos fundamentos macroeconômicos e outro mais susceptível a problemas de políticas macroeconômicas não críveis.

Nesse contexto pode-se obter novos escores onde os pesos dos desvios da inflação e do produto são positivos, conforme equação 5.2 apresentada a seguir. Note que a função de perda à Barro-Gordon apresentada em (5.1) apresenta sinal positivo para os desvios da inflação e sinal negativo para os desvios do produto. Nesse contexto os países que apresentam menores escores estão minimizando suas perdas com menores desvios da inflação e 
maiores desvios do produto (proxy para maiores desvios do nível de emprego ou menores desvios para o desemprego.

Maiores escores resultante da equação 5.2 são decorrentes de maiores desvios da inflação e maiores desvios do produto (menores desvios de desemprego). Tais escores indicam economias com problemas nos fundamentos. Por outro lado, menores escores são resultantes de menores desvios da inflação e menores desvios dos produtos (maiores desvios do desemprego). Tais escores indicam problemas de políticas macroeconômicas não críveis. Dessa forma, pode-se separar os 20 países do grupo 1 em dois subgrupos por meio da ordenação dos escores, calculados conforme a seguir:

Escore

$(I)=0,11 *\left(\Pi_{t}\right)^{2}+0,45 *\left(\Pi_{t-1}\right)^{2}+0,25 *\left(y_{t}\right)^{2}+0,18 *\left(y_{t-1}\right)^{2}(5.2)$

Os valores padronizados das variáveis $\left(\Pi_{t}\right)^{2},\left(\Pi_{t-1}\right)^{2},\left(y_{t}\right)^{2} \mathrm{e}$ $\left(\mathrm{y}_{\mathrm{t}-1}\right)^{2}$ estão relacionados na Tabela 5 e os escores estão relacionados na Tabela 6 , conforme a segue.

Tabela 5: Valores padronizados das variáveis do Grupo 1

\begin{tabular}{lcccc}
\hline $\begin{array}{c}\text { Paises e biênio } \\
\text { Pré-crise }\end{array}$ & $\left(\Pi_{\mathrm{t}-1}\right)^{2}$ & $\left(\Pi_{\mathrm{t}}\right)^{2}$ & $\left(\mathbf{y}_{\mathrm{t}-1}\right)^{2}$ & $\left(\mathbf{y}_{\mathbf{t}}\right)^{2}$ \\
\hline Argentina-95/96 & $-0,37$ & $-0,66$ & $-1,49$ & 1,27 \\
Bélgica-91/92 & $-0,36$ & $-0,58$ & $-0,12$ & $-0,38$ \\
Brasil-95/96 & 1,70 & $-0,14$ & $-0,39$ & 0,21 \\
Brasil-97/98 & $-0,24$ & $-0,56$ & 0,33 & $-0,93$ \\
Colômbia -95/96 & 0,21 & 0,00 & 0,96 & $-0,17$ \\
Dinamarca-91/92 & $-0,39$ & $-0,59$ & $-0,26$ & $-0,55$ \\
Espanha-91/92 & $-0,27$ & $-0,47$ & $-0,07$ & 1,73 \\
França-91/92 & $-0,37$ & $-0,58$ & $-0,49$ & $-0,55$ \\
Hong Kong-95/96 & $-0,18$ & $-0,45$ & 0,39 & 0,84 \\
Itália-91/92 & $-0,27$ & $-0,50$ & $-0,35$ & 0,84 \\
Jordânia-95/96 & $-0,18$ & $-0,45$ & 0,99 & $-0,72$ \\
México-93/94 & $-0,15$ & $-0,44$ & $-0,15$ & 0,59 \\
México-95/96 & 0,67 & 0,47 & $-2,46$ & 1,14 \\
Peru-95/96 & $-0,10$ & $-0,28$ & $\mathbf{1 , 3 9}$ & 0,00 \\
R.Unido-91/92 & $-0,28$ & $-0,54$ & $-1,12$ & $-1,01$ \\
R.Tcheca-95/96 & $-0,18$ & $-0,37$ & 1,13 & 0,59 \\
R.Tcheca-95/96 & $-0,18$ & $-0,37$ & 1,13 & 0,59 \\
\hline
\end{tabular}


(Continuação...)

\begin{tabular}{lcccc}
\hline $\begin{array}{c}\text { Países e biênio } \\
\text { Pré-crise }\end{array}$ & $\left(\Pi_{t-1}\right)^{2}$ & $\left(\Pi_{\mathbf{t}}\right)^{2}$ & $\left(\mathbf{y}_{t-1}\right)^{2}$ & $\left(\mathbf{y}_{\mathbf{t}}\right)^{2}$ \\
\hline Sri Lanka-95/96 & $-0,22$ & $-0,14$ & 0,88 & 0,55 \\
Suécia-91/92 & $-0,19$ & $-0,59$ & $-1,15$ & $-1,69$ \\
Turquia-95/96 & 2,41 & 1,97 & 1,36 & 1,90 \\
Venezuela-95/96 & 1,50 & 2,62 & 0,42 & $-1,14$ \\
\hline
\end{tabular}

Substituindo-se os valores padronizados da Tabela 5 na equação 5.2, obtêm-se os escores para cada país conforme apresentado a seguir.

Tabela 6: Escores estimados: função perda de Barro-Gordon (Grupo 1)

\begin{tabular}{|c|c|c|c|}
\hline $\begin{array}{l}\text { Suécia- } 91 / 92 \\
-0,78011\end{array}$ & $\begin{array}{c}\text { Bélgica- } 91 / 92 \\
-0,34425\end{array}$ & $\begin{array}{c}\text { Hong Kong-95/96 } \\
0,15219\end{array}$ & $\begin{array}{l}\text { RTcheca- } 95 / 96 \\
0,23140\end{array}$ \\
\hline R.Unido-91/92 & Brasil-97/98 & Peru-95/96 & Espanha-91/92 \\
\hline & & & \\
\hline $\begin{array}{c}\text { França-91/92 } \\
-0,45466\end{array}$ & $\begin{array}{c}\text { Argentina }-95 / 96 \\
-0,19089\end{array}$ & $\begin{array}{c}\text { Sri Lanka-95/96 } \\
0,17961\end{array}$ & $\begin{array}{c}\text { Venezuela-95/96 } \\
0,75132\end{array}$ \\
\hline Itália-91/92 & Jordânia-95/96 & México-95/96 & Brasil-95/96 \\
\hline & 7 & & \\
\hline $\begin{array}{c}\text { Dinamarca }-91 / 92 \\
-0,42647\end{array}$ & $\begin{array}{c}\text { México-93/94 } \\
0,00532\end{array}$ & $\begin{array}{c}\text { Colômbia-95/96 } \\
0,22734\end{array}$ & $\begin{array}{l}\text { Turquia-95/96 } \\
\mathbf{2}, 02242 \\
\end{array}$ \\
\hline
\end{tabular}

Utilizando os mesmos métodos estatísticos da análise de classificação obtiveram-se dois subgrupos:

Subgrupo 1: Suécia, Reino Unido, França, Itália, Dinamarca, Bélgica, Brasil-97/98 e Argentina;

Subgrupo 2: Jordânia, México-93/94, Hong-Kong, Peru, Sri Lanka, México-95/96, Colômbia, R.Tcheca, Espanha, Brasil-95/96 e Turquia.

Os resultados da análise de classificação demonstram que os países com maiores escores (Subgrupo 2) estavam mais vulneráveis às crises decorrentes de má performance dos fundamentos macroeconômicos, i.e., permuta de baixas taxas de desemprego (elevadas taxas de crescimento econômico) por elevadas taxas de inflação. Por outro lado, os países que apresentam menores escores (Subgrupo 1) mostram-se vulneráveis às crises decorrente de políticas macroeconômicas não críveis. 
Pode-se observar ainda que o Brasil no biênio 1995/96 apresenta um elevado escore, que sugere problemas nos fundamentos macroeconômicos (combinação de maiores taxas inflacionárias com menores taxas de desemprego ou maiores taxas de crescimento do produto real). Este resultado indica que o Brasil no início do Plano Real (1995/96) apresentava problemas nos fundamentos, mas, com o decorrer da administração do Plano, a má performance dos fundamentos foi sendo sanada. Com o decorrer dos anos, a taxa de inflação arrefeceu-se, mas às custas de maior desemprego, o que deslocou a economia de uma posição que sugere problemas nos fundamentos em 1995/96 para uma posição que sugere problemas de credibilidade de política econômica em $1997 / 98$.

\section{Conclusões}

A estimativa da função de perda à Barro-Gordon (1983) para um grupo de 28 países indica que os principais protagonistas da crise asiática (Coréia, Filipinas, Malásia, Indonésia e Tailândia), além da China, Cingapura e Chile no biênio 1995/96, foram classificados como os países menos vulneráveis a crises cambiais. Esses resultados foram assegurados por tais países apresentarem menores escores da função de perda, resultante de menores taxas de inflação e de maiores taxas de crescimento do produto real, uma proxy para menores taxas de desemprego.

O grupo de 20 países que apresentaram maiores escores da função de perda sugere maior possibilidade de ocorrência de crise cambial. Para perdas originadas por elevadas taxas de inflação, atribui-se a provável crise a problemas nos fundamentos macroeconômicos. Para as perdas originadas por elevadas taxas de desemprego (menores taxas de crescimento do produto real), associadas a baixas taxas de inflação, atribui-se a provável crise a falta de credibilidade para a manutenção da política de câmbio fixo ou administrado. Assim, estimaram-se novos escores para determinar quais países estavam mais propensos às crises cambiais explicadas pela má performance dos fundamentos macroeconômicos, e aqueles que estão mais propensos às crises decorrente de políticas não críveis.

Os resultados apresentados corroboram os resultados apontados pela literatura a respeito dos países pertencentes ao Sistema Monetário Europeu, que sofreram crise em 1992 e 1993. Exceto a 
Espanha, observa-se que Suécia, Reino Unido, Itália, França, Dinamarca e Bélgica apresentaram os menores escores, decorrentes de menores taxas de inflação às custas de maiores taxas de desemprego (menores taxas de crescimento do produto real), indicando que estavam vulneráveis às crises decorrentes de políticas econômicas não críveis, isto é, políticas em que o custo para manter o câmbio fixo era maior do que os benefícios. Esse resultado vem corroborar a posição da literatura, a exemplo de Krugman (1996), Rose e Svensson (1994), Knot, Sturm e Haan (1998) e Obstfeld e Rogoff (1995). O advento da crise do SME é o exemplo mais citado de crise auto-realizável, que redundou na família dos modelos de segunda geração.

Um outro resultado interessante é que o Brasil no biênio (1997/98), anterior à crise cambial de janeiro de 1999, apresenta um escore próximo aos países do SME. Trata-se de um indicador de que o Brasil neste período estava susceptível às crises autorealizáveis. A literatura enfatiza que a crise cambial brasileira deve-se a problemas de credibilidade das políticas econômicas adotadas durante o Plano Real. A idéia é que a política não era crível, pois os custos para sua manutenção foram muito elevados, com altas taxas de desemprego e um forte crescimento da divida pública. Para um melhor entendimento ver Drazen e Masson (1994), Giambiagi e Moreira (1999) e Arbex e Fontes (1999). Na linha dos modelos de primeira geração, Menezes e Moreira (2001) descartam a possibilidade da crise brasileira de 1999 ter sido explicada pelo Modelo de Krugman (1979), em outras palavras, rejeitam a hipótese de crise nos fundamentos como causa do ataque ao Real.

\section{Referências bibliográficas}

ANDRADE, J. P.; FALCÃO, M. L. Divergência e Convergências sobre as Crises Cambiais. Em: Macroeconomia Moderna - Keynes e a economia contemporânea. Organizadores: LIMA,G. T.; Sicsú, J. e DE PAULA, L. F. Rio de Janeiro: Editora Campus, 1999.

ARBEX, M. A; FONTES, R. Credibilidade das Políticas Econômicas no Brasil: Uma Análise Empírica do Período 1991-1998. Economia Aplicada, v.3, n.1, 1999.

BARRO, R. J.; GORDON, D. B. A Positive Theory of Monetary Policy in a Natural Rate Model. Journal of Political Economy. v.91, n.41: 589-609, 1983.

EICHENGREEN, B. A Globalizaçāo do Capital. Sāo Paulo: Editora 34. Trad por Sergio Blum de Globalizing capital (New Heaven: Princeton University Press), 2000. 
EVERITT, B.S.; DER, G. A Handbook of Statistical Analyses Using SAS. Nova York: Chapman G Hall, 1996.

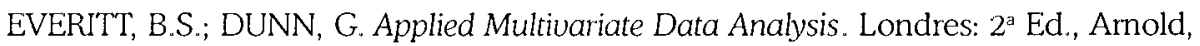
2001 .

FLOOD, R. P.; GARBER, P.M. Collapsing exchange-rate regimes: some linear examples. Journal of International Economics, v. 17, n. 1/2: 1-13, 1984.

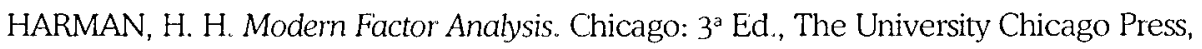
1976.

International Monetary Fund. International Financial Statistics (fevereiro e anual), 1999. KAMINSKY, G.; REINHART, C. M. The twin crises: the causes of banking and balance-ofpayments problems. The American Economic Review, v.89, n.3 (junho): 473-500, 1999.

KNOT, K.; STURM, Jan-E.; HAAN, J. de. The credibility of the European exchange rate mechanism. Oxford University Press, v. 50: 186-200, 1998.

KRUGMAN, P. A model of balance of payments crises. Joumal of Money, Credit and Banking, V. 11, (agosto): 311-25, 1979.

KRUGMAN, P. Are Currency Crises Self-Fulfilling? NBER Macro Annual Conference, março, 1996.

MANLY, B. F.J. Multivariate Statistical Methods - A Primer. Londres: $2^{a}$ Ed., Chapman E Hall, 1994. MENEZES, A. C.; MOREIRA, T. B. S. O Modelo de Krugman Explica a Crise Cambial Brasileira em Janeiro de 1999? Análise Econômica, ano 19, 1.36, 2001.

MOREIRA, T. B. S. Fatores Determinantes de Crises Cambiais e Bancárias. Revista Econômica do Nordeste, Fortaleza, v.33, n.2, abr-jun. 2002.

MOREIRA, T. B. S. Vulnerability Indicators of The Twin Crises: The East Asian Episode. Análise Econômica, Ano 21, № 40, Setembro 2003.

MOREIRA, T. B. S.; PINTO, M. B. de P; SOUZA, G. da S. Uma metodologia alternativa para mensuração de pressão sobre o mercado de câmbio. Estudos Econômicos, Vol.34, n. I, p: 73-100, 2004.

OBTSFELD, M.; ROGOFF, K. The Mirage of Fixed Exchange Rates. Journal of Economic Perspectives, v.9, n.4, (winter): 73-96, 1995.

OBSTFELD, M.; ROGOFF, K. Foundations of International Macroeconomics. Londres: $2^{\mathrm{a}}$ Ed., The MIT Press, 1997.

ROSE, A. K.; SVENSSON, L. E. O. European exchange rate credibility before the fall. European Economic Review, v. 38: 1185-1216, 1994.

TABACHNICK, B. G. FIDELL, L. S. Using Multivariate Statistics. Boston: $4^{a}$ Ed. Allyn and Bacon, 2001.

VELASCO, A. Fixed exchange rates: credibility, flexibility and multiplicity. European Economic Review, v. 40: 1023-1035, 1996.

WICHERN, D. W.; JOHNSON, R. A. Applied Multivariate Statistical Analysis. Londres: $3^{\text {a Ed, }}$ Englewood (N.J.): Prentice-Hall, Inc, 1998. 